\title{
A Study on Work Stress and Job Satisfaction among Headmasters: A Case Study of Bilingual Schools in Sultanate of Oman - Muscat
}

\author{
Dr. Arvind Hans \\ Assistant Professor, Department of Management \\ Waljat College of Applied Sciences, \\ P.O. Box 197, Rusayl, P.C. 124, Muscat, Sultanate of Oman \\ Email: arvind@waljat.net \\ Dr. Soofi Asra Mubeen \\ Assistant Professor, Department of Management \\ Waljat College of Applied Sciences, \\ P.O. Box 197, Rusayl, P.C. 124, Muscat, Sultanate of Oman \\ Email: soofiam@rediffmail.com \\ Mr. Sultan Khan \\ Assistant Professor, Department of Management \\ Waljat College of Applied Sciences, \\ P.O. Box 197, Rusayl, P.C. 124, Muscat, Sultanate of Oman \\ Email: sultankhan@waljat.net \\ Mr. Abdulla Said Mohammed Al Saadi \\ Waljat College of Applied Sciences
}

Doi:10.5296/jsr.v5i1.5426

URL: http://dx.doi.org/10.5296/jsr.v5i1.5426

\begin{abstract}
The Study made an attempt to identify the work stress and job satisfaction among headmasters of bilingual school in Muscat, Sultanate of Oman. Work stress and Job Satisfaction are vital organizational issues affecting performance and growth of an organization in emerging competitive environment. Descriptive research design was adopted and simple random sampling with a sample of 40 headmasters of bilingual schools in Muscat was chosen for the study. The data was collected through two structured questionnaires on job satisfaction and work stress. The data was analyzed and reported through descriptive statistics. Result indicated that the headmasters of bilingual schools were more likely to experience stress at work and had a high level of Job satisfaction in their challenging work.
\end{abstract}

Keywords: Bilingual schools, Headmasters, Job satisfaction, Work Stress. 


\section{Introduction}

Oman government has shown much concern in the area of development of human resources in all sectors. Educational institutions play an important role in the development of human resource in a developing society. Headmasters are one of the important elements in the overall growth and development of educational institutions. They affect the relationship with teachers, students and management in school which has a significant impact on job satisfaction and work stress. Their satisfaction helps in achieving the objectives of educational system effectively and efficiently. Job satisfaction and work stress are important factors considered in bilingual schools as the quality of education depends on the satisfaction level of headmasters and teachers as their best efforts make school environment more conducive for better pedagogy. Bilingual schools are those institutions where lecture delivery is done in more than one language (Arabic and English). Since, it is not possible to completely separate language and culture of a nation, the term bilingual education includes the concept of bicultural education (Ovando and Collier 1985).Job satisfaction among headmasters can positively or negatively influence the performance on organizational goals. Headmasters dissatisfied from their job show negative attitude towards work and will feel stressed on their jobs. Stress can be physical or psychological. It is a state of tension which is experienced by individuals facing extraordinary demands and constraints in their assigned jobs; whereas Job Satisfaction has been conceptualized as an overall pleasant and positive attitude possessed by an employee towards the job in an organization. The descriptive study focused on observing the phenomena of work stress and job satisfaction in bilingual schools in Oman among Headmasters.

\section{Literature Review}

Review of literature was carried out to report the studies related to Work stress and Job Satisfaction. Following studies examined the underlying phenomena and relationship between Work stress and Job satisfaction which provide a basis to find out the research gap for the present study.

Parsa et.al., (2013) examined the relationship between job stress and job satisfaction and responsiveness among 259 teachers in high schools of Urmia city. Parametric and non parametric test was used for the analysis. The result revealed that there was a significant and positive relationship between responsiveness and job satisfaction and significant and positive relationship between job satisfaction and job stress. A linear relationship was found between responsiveness of teachers, job satisfaction, age and job background. There was no relationship found between responsiveness and job stress. Peters, J (2013) made an exploratory study in the work load of Waldorf teachers using an open design. It was found that teachers coped positively with the stresses and strains of teaching when school supported them at all levels of school's activities. An empirical study was done by Kayastha, D.P \& Kayastha, R. (2012) on the relationship between teachers stress and job satisfaction facets with a particular reference to corporate, higher secondary school teachers from Kathmandu and latitpur districts of Nepal. The result showed the significant relationship between Job stressors, Job stress and Job satisfaction. Similarly Wang, L (2012) focused on three hundred primary and junior high school teachers to know the level of work stress and job satisfaction. 
Result revealed that work stress and job satisfaction of teachers were found average in such schools. Necsoi,V.D (2011) identified the relationship between stress and job satisfaction among 70 University teachers of Romanian academics. Burns Anxiety Inventory, Burns Depression Inventory and Warr Job satisfaction scale by Travers and Cooper were used and the result indicated that there was a negative correlation between stress and job satisfaction. High level of anxiety \& depression were observed among female teachers. A low level of job satisfaction was found among female teachers, where male counterparts were found significantly opposite on these scales. Academic tenure showed substantially greater job satisfaction among them. Bhatti et.al. (2011) investigated the relationship between job stress and job satisfaction among 400 university teachers in Pakistan. Management role, relationship with others, workload pressure, homework interface, role ambiguity and performance pressure was examined as determinants of job stress and the result revealed that there was a significant relationship between four of the constructs tested and there is significant negative relationship between job stress and job satisfaction. Result revealed that job stress had negative impact on their health. Kaur, S (2011) also made an attempt to examine the job satisfaction and occupational stress of the school teachers with a sample of 500 secondary school teachers. It was found that male teachers were more satisfied with their jobs and occupationally less stressed than the female teachers. It was also observed that rural school teachers were less satisfied and had relatively higher level of occupational stress as compared to urban school teachers. Klassen et.al.,(2010) studied on teachers collective efficacy (TCE), job stress, cultural dimension (Collectivism) and job satisfaction on 500 teachers from Canada, Korea and the United states. Multi group path analysis revealed that TCE predicted job satisfaction across settings. Job stress was negatively related to job satisfaction for North American teachers. The cultural dimension of collectivism was not related to job satisfaction in Korean and North American teachers. De Nobile, J.John \& Mc Cormick, J (2005) investigated the relationship between job satisfaction and occupational stress among 356 staff members from 52 primary schools of 6 catholic school systems in New South Wales, Australia and identified nine job satisfaction and four occupational stress factors through factor analysis. Moderate to strong correlations existed between most of the job satisfaction and occupational stress variables.

Literature related to Work Stress and Job Satisfaction was based on the study of primary and secondary school teachers in different countries. Most of the study showed the positive correlation between work stress and Job satisfaction in school and college among teachers. Few study also revealed the gender difference in experiencing work stress and level of job satisfaction in teaching profession. Some study focused on the impact of tenure on work stress and job satisfaction, even the location of school showed impact on two related phenomena. Few studies have focused on job satisfaction and work stress among principal or headmasters in educational institutions across the world. Present study made an attempt to identify and report the phenomena related to the work stress and job satisfaction among head masters of bilingual schools in Sultanate of Oman. The study also made an attempt to add value in existing literature of both referred phenomena in bilingual schools among headmasters across the world. 


\section{Significance of the Study}

Job satisfaction and work stress are associated very closely in the working environments and that's why certain behaviors appear at work such as organizational citizenship behavior (OCB), employee commitment and absenteeism. This study is important because of the following:

a. Job satisfaction and job performance is directly related to one another. Thus it can be inferred that a happy worker is a productive worker.

b. It gives clear evidence that dissatisfied employees skip work more often and more likely to resign. Satisfied worker are likely to work longer with the organizations.

c. This study will help to find out the level of work stress and job satisfaction among headmasters in bilingual school in Oman.

\section{Objectives of the Study}

a. To study the level of job satisfaction among headmasters of the bilingual school.

b. To identify the work stress among headmasters of the bilingual school.

c. To describe the phenomena related to Job Satisfaction and Work Stress among headmasters in bilingual schools, Muscat.

\section{Scope of the study}

The study investigated the phenomena related to work stress and job satisfaction among headmasters of bilingual schools in Oman from an academic point of view. The study identified the level of work stress and job satisfaction among headmasters which helped the headmasters to manage their time and effort for the purpose of reducing the work stress and to improve the level of satisfaction on their job.

\section{Research Methodology}

Descriptive Research Design was used for this research based on adoption of survey method.

\subsection{Sampling Design}

Simple Random Sampling method was adopted for this study.

\subsection{Sample Size}

The total sample size in the present study was 40 headmasters / deputies from the bilingual schools in Muscat - Sultanate of Oman.

\subsection{Sample Unit}

Sample unit consisted of headmasters/ deputies of bilingual schools in Muscat - Sultanate of Oman.

\subsection{Data Collection Method(s)}

Both primary and secondary data were used.

- Primary Data: The data was collected through two structured Questionnaire of Work stress and Job Satisfaction.

- Secondary Data: The data was collected through the following sources:

$\circ$ Books and Journal research articles

○ EBSCO research data base \& Internet 


\section{MInstitute"}

\section{Data Analysis Method}

The data collected from the sample was analyzed by using descriptive statistics from the statistical tools.

\section{Results and Discussion}

Job satisfaction is a widely studied aspect of industrial psychology and it has been viewed by the industrial psychologist that the job satisfaction is a pleasant and positive attitude possessed by an employee towards his job. The following table exhibited the job satisfaction score range and category. The job satisfaction questionnaire was interpreted based on the score given below.

Table 1: Score range and the finding on Job Satisfaction of Headmasters

\begin{tabular}{|c|l|}
\hline Score range & Category \\
\hline $25-32$ & Very highly satisfied \\
\hline $\mathbf{2 1 - 2 4}$ & Highly satisfied \\
\hline $16-20$ & Moderately satisfied \\
\hline $12-15$ & Moderately dissatisfied \\
\hline $8-11$ & Highly dissatisfied \\
\hline $0-7$ & Very highly dissatisfied \\
\hline
\end{tabular}

Table 1 showed the score range scale of job satisfaction. The score was calculated as 23.8. This was categorized at higher level of job satisfaction scale. It clearly indicated that headmasters were highly satisfied with their jobs even they face little stress at work within the school hours. It can be inferred that the increased level of job satisfaction was there because of decent pay scale at school level. The facility provided by the college administration and parity and fairness in salary has positively impacted the level of job satisfaction. The long tenure as headmaster with the school can also be one of the factors which have impacted the level of job satisfaction at higher level.

Table 2: Score range on Work Stress

\begin{tabular}{|l|l|}
\hline Range points & Description \\
\hline 4 points or less & None or likely little \\
\hline $5-13$ & Normal or likely high \\
\hline 14 or more & Likely more high \\
\hline
\end{tabular}

Table 2 showed the score range points of work stress which describes that 4 points or less are least likely to suffer from stress related illness. 5-13 range points are more likely to experience stress causing ill health either mental, physical or both. 14 points or more are the most prone to stress showing a great traits or characteristics that are creating unhealthy 
behaviors.

Table 3: Finding of Work stress among Headmasters

\begin{tabular}{|l|l|}
\hline Range points & Description \\
\hline 11.6 & Normal or likely high \\
\hline
\end{tabular}

Table 3 revealed the result of work stress among Head masters and it was found in an average range. The score was found between the ranges of 5-13 points. It can be inferred that head masters of bilingual schools in Oman are more likely to experience work stress causing ill health either mental, physical or both. A relatively high level of work stress was because of the volume of work and responsibility they had in schools. Availability and efficiency of administrative staff and teacher also impacted the increased level of stress among head masters in Bilingual school of Oman. It was also inferred that tight packed work hours, and insufficient leisure time also compounded the stress among them.

\section{Conclusions:}

The aim of this paper was to study on Work Stress and Job Satisfaction among Headmasters of Bilingual schools in Oman. The presence of stress at work place is certain in most of the job. When the stress of the employees increases it affects the performance on the job and health of the employee across the institutions. Headmaster felt stress due to heavy workload, time pressure, poor working environment etc. It was found from the study that the Headmasters of Bilingual schools in Oman were highly satisfied with their Jobs and also more likely to experience stress related to ill health both physical and psychological. As the performance of the school depends upon the active performance of the headmasters, proper training has to be given to the headmasters to prepare them for managing or dealing with stress and achieve high job satisfaction. The phenomena related to Job satisfaction and work stress among headmasters in bilingual schools was found similar to others studies in the past. However, the study may bring clear understanding of these phenomena in this sector and add little more value in the literature for better generalization across culture.

\section{Directions for Future Research}

a. Further study can be done with a large sample size for better understanding and generalization of findings on work stress and job satisfaction of headmasters in Bilingual Schools in Oman.

b. A similar type of study can be done on headmasters/principles in other country.

c. A similar type of study can be done on primary and secondary school teachers in Oman.

d. Inferential study on work stress and job satisfaction can be done on headmasters of all types of schools in Oman.

\section{References}

Parsa,S., Alizadeh,S., Kasraie, S. (2013). The Investigation of relationship between job stress and job satisfaction and responsiveness (accountability) of teachers in high schools of Urmia city. International Journal of Educational Science and Research.Vol.3, Issue 1, Pg 89-98. ISSN: 2249-6947. 


\section{Macrothink}

Journal of Sociological Research

ISSN 1948-5468

2014, Vol. 5, No.1

Klassen.M.R., Usher ,L.E., Bong, M (2010). Teachers collective efficacy, Job satisfaction and Job stress in cross cultural context. The Journal of Experimental Education. 78, $464-468$. ISSN: 0022-0973.

De Nobile, J.John \& Mc Cormick, J (2005). Job satisfaction and Occupational Stress in Catholic Primary Schools. Paper presented at the Annual conference of the Australian Association for Research in Education, Sydney, No 27 - Dec 1.

Kaur, S (2011). Job satisfaction and Occupational Stress among school teachers: A correlation study. International Referred Research Journal,Vol.3, Issue 32. Pg 49-50, ISSN: 0974-2832. Bhatti, N.,Hashmi A.M., Raza,A.S., Shaikh, M.F., Shafiq,K. (2011). Empirical Analysis of Job Stress on Job Satisfaction among University Teachers in Pakistan. International Business Research, Vol.4, No.3 Pg 264- 270. ISSN: 1913-9004.

Kayastha, D.P \& Kayastha, R. (2012). A study of Occupational Stress on Job Satisfaction among teachers with particular reference to corporate, higher secondary school of Nepal: Empirical Study. Asian Journal of Management Sciences and Education, Vol.1, No.2, Pg 52-62. ISSN: 2186-8441.

Necsoi,V.D. (2011). Stress and Job satisfaction among University Teachers. International Conference of Scientific paper. AFASES 26-28 May. Pg 320-325.

Peters, J. (2013). Workload, Stress and Job satisfaction among Waldorf teachers: An Explorative Study. RoSE - Research on Steiner Education. Vol 3, No.2 Pg 111-117. ISSN 1891-6511.

Ojha,H “Organizational Job Satisfaction Questionnaire” MANASVI, National Psychological Corporation.

Ovando, C. J., Collier, V. P., \& Combs, M. C. (1985). Bilingual and ESL classrooms: Teaching in multicultural contexts (Vol. 85). New York: McGraw-Hill.

http://www.isma.org.uk/wp-content/uploads/2013/08/Stress- Questionnaire.pdf

Wang, L. (2012). A survey on Work stress and Job Satisfaction of Primary and Junior High School Teachers. International Conference on Technology and Management Lecture Notes in Information Technology, Vol.21.

\section{Glossary}

TCE $=$ Teachers collective efficacy 